\title{
Editorial
}

\section{A Disclosure Form for Work Submitted to Medical Journals}

\author{
A Proposal From the International Committee of Medical Journal Editors*
}

\author{
Darren B. Taichman, Joyce Backus, Christopher Baethge, Howard Bauchner, Annette Flanagin, \\ Fernando Florenzano, Frank A. Frizelle, Fiona Godlee, Laragh Gollogly, Abraham Haileamlak, \\ Sung-Tae Hong, Richard Horton, Astrid James, Christine Laine, Pamela W. Miller, Anja Pinborg, \\ Eric J. Rubin, Peush Sahni
}

$\mathrm{M}$ any factors, including professional and personal relationships and activities, can influence the design, conduct, and reporting of the clinical science that informs health care decision. The potential for conflict of interest exists when these relationships and activities may bias judgement (1). Many stakeholders - editors, peer reviewers, clinicians, educators, policymakers, patients, and the public - rely on the disclosure of authors' relationships and activities to inform their assessments. Trust in the transparency, consistency, and completeness of these disclosures is essential.

Ten years ago, the International Committee of Medical Journal Editors (ICMJE) adopted the "ICMJE Form for the Disclosure of Potential Conflicts of Interest" as a uniform mechanism for collecting and reporting authors' relationships and activities that readers might consider relevant to a published work (2). The goal was to avoid the confusion (and often ensuing controversy) created when journals vary in how they collect and report this information. We believe a uniform disclosure form has been helpful, but problems remain. First, the software supporting the current form is increasingly problematic, making its use difficult or impossible for an increasing number of authors. More important, however, is that many authors and readers misunderstand, misapply, or misinterpret the disclosures.

Although some individuals violate the public trust by purposefully hiding relevant relationships and activities, we believe most authors are committed to transparent reporting and consider it as vital to the advancement of clinical science. Nonetheless, disagreement, confusion, and controversy regarding authors' disclosures arise when opinions differ over which relationships and activities to report. An author might not report an item that others deem important because of a difference in opinion regarding what is "relevant," confusion over definitions, or a simple oversight. Some authors may be concerned that readers will interpret the listing of any item as a "potential conflict of interest" as indicative of problematic influence and wrongdoing, a concern often raised regarding the requirement to report publicly funded grants. For their part, some readers fail to recognize that their own relationships and activities influence how they assess the work of others and what they deem to be a "conflict" for others or themselves.

\footnotetext{
* The International Committee of Medical Journal Editors (ICMJE) is a working group formed by editors of scientific medical journals, which comments on technical, organizational, and political questions in medical publishing. The ICMJE has not only made suggestions for declaring conflicts of interests, but also for reference style, authorships, clinical trial registration, and data sharing. It also publishes the Recommendations for the Conduct, Reporting, Editing and Publication of Scholarly Work in Medical Journals, which constitute an important resource for many authors and journals. At present, the ICMJE has the following members: Annals of Internal Medicine, The BMJ (British Medical Journal), the Bulletin of the World Health Organization, Deutsches Ärzteblatt, the Ethiopian Journal of Health Sciences, JAMA (Journal of the American Medical Association), the Journal of Korean Medical Sciences, the New England Journal of Medicine, the New Zealand Medical Journal, Revista Médica de Chile, The Lancet, Ugeskrift for Laeger (Denmark), the National Library of Medicine (USA), and the World Association of Medical Editors (WAME). The committee's office is located in the Annals of Internal Medicine in Philadelphia.
} 
We propose several changes to the ICMJE disclosure form to help address these issues. First, words matter. Despite including the word "potential," a form entitled "...for the Disclosure of Potential Conflicts of Interest" may imply that any relationship or activity listed represents a problematic influence or wrongdoing. The proposed new title, "The ICMJE Disclosure Form," aims to dispel that interpretation and potential stigma. Second, we no longer ask authors to decide what might be interpreted as a potential conflict of interest. Authors disclose their relationships and activities so that readers can decide whether these relationships or activities should influence their assessments of the work. Further, to avoid omissions-inadvertent or purposeful-we now provide a checklist of relationships and activities for authors to complete.

We welcome feedback about the proposed new form, which is available with a link to provide comments, at www.icmje.org. We will consider comments received by 30 April 2020, before finalizing and adopting a revised version. In the interim, the extant "ICMJE Form for the Disclosure of Potential Conflicts of Interest" will remain in use and available as a downloadable PDF at our website.

In a further step to avoid inconsistencies and omissions, and to help ease the disclosure process for authors, some journals will change the mechanism by which disclosures are collected. Authors are required to provide disclosures to multiple entities (e.g., to academic institutions, continuing education providers, guideline and other committees as well as medical journals). Disclosing information repeatedly, with varying reporting requirements, formats, and definitions, is frustrating for authors and contributes to problematic and controversial discrepancies across disclosures. The ICMJE will therefore accept disclosures from webbased repositories. These enable authors to maintain an inventory of their relationships and activities and create electronic disclosures tailored to the requirements of entities such as ICMJE, without having to reenter information repeatedly.

ICMJE will accept disclosures from repositories that meet the following criteria: collection and reporting of relationships and activities consistent with ICMJE requirements; no fees for individuals to enter, store, or export their data; provision of disclosures to journals electronically as well as an option for journals without a digital interface; and compliant with the General Data Protection Regulation (GDPR).

One currently available repository that is consistent with these criteria is Convey (www.convey. org), but we encourage the development of other repositories as necessary to meet regional, linguistic, and regulatory needs. A template that enables authors to create disclosures that emulate the extant "ICMJE Form for the Disclosure of Potential
Conflicts of Interest" is already available at the Convey platform, and some of our journals have begun to collect author disclosures electronically in this way. This template will be updated to conform to the new ICMJE Disclosure Form when it is finalized, and all ICMJE journals can begin accepting disclosures in this manner. Ultimately, the currently employed PDF-based ICMJE form will be unavailable.

While no approach to disclosure will be perfect or foolproof, we hope the changes we propose will help promote transparency and trust. We look forward to your feedback.

\section{Conflict of interest statement}

Darren B. Taichman is an employee of the Annals of Internal Medicine and the American College of Physicians.

\section{Christopher Baethge is an editor of a medical journal (Deutsches} Ärzteblatt) and employed by a publishing house (Deutscher Ärzteverlag).

Annette Flanagin is a non-paid board member of STM: International Association of Scientific, Technical, and Medical Publishers.

Abraham Haileamlak is the Editor of Ethiopian Journal of Health Sciences and member of ICMJE.

Christine Laine is a full time employee of the American College of Physicians and serves as Senior Vice President of the organization and the Editor in Chief of Annals of Internal Medicine. The journal is owned and published by the ACP.

The remaining authors declare that no conflict of interest exists.

\section{References}

1. ICMJE: Recommendations for the conduct, reporting, editing, and publication of scholarly work in medical journals. www.icmje.org/ icmje-recommendations.pdf (last accessed on 17 December 2019).

2. Drazen JM, Van Der Weyden MB, Sahni P, et al.: Uniform format for disclosure of competing interests in ICMJE journals. www.icmje.org/news-and-editorials/format disclosure coi_oct2009.pdf (last accessed on 17 December 2019).

\section{Affiliations}

Darren B. Taichman, MD, PhD*, Secretary, ICMJE, Executive Editor, Annals of Internal Medicine

Joyce Backus, MSLS, Representative and Associate Director for Library Operations, National Library of Medicine

Christopher Baethge, MD, Chief Scientific Editor, Deutsches Ärzteblatt (German Medicine Journal) \& Deutsches Ärzteblatt International

Howard Bauchner, MD, Editor-in-Chief, JAMA (Journal of the American Medical Association) and the JAMA Network

Annette Flanagin, RN, MA, Executive Managing Editor, Vice President, Editorial Operations, JAMA (Journal of the American Medical Association) and the JAMA Network

Fernando Florenzano, MD, Editor, Revista Medica de Chile (Medical Journal of Chile)

Frank A. Frizelle, MBChB, FRACS, Editor-in-Chief, New Zealand Medical Journal

Fiona Godlee, MBBChir, BSc, Editor-in-Chief, The BMJ (British Medical Journal)

Laragh Gollogly, MD, MPH, Editor, Bulletin of the World Health Organization, Coordinator, WHO Press

Abraham Haileamlak, MD, Editor-in-Chief, Ethiopian Journal of Health Sciences

Sung-Tae Hong, MD, PhD, Editor-in-Chief, Journal of Korean Medical Science

Richard Horton, FMedSci, Editor, The Lancet

Astrid James, MBBS, Deputy Editor, The Lancet

Christine Laine, MD, MPH, Editor-in-Chief, Annals of Internal Medicine 
Pamela W. Miller, BA, Assistant to the Editor, Special Projects, New England Journal of Medicine

Anja Pinborg, MD, Scientific Editor-in-Chief, Ugeskrift for Laeger (Danish Medical Journal)

Eric J. Rubin, MD, PhD, Editor-in-Chief, New England Journal of Medicine Peush Sahni, MBBS, MS, PhD, Representative and Past President, World Association of Medical Editors

Corresponding author:

Darren B. Taichman, MD, PhD*

Secretary, ICMJE, Executive Editor, Annals of Internal Medicine

190 N. Independence Mall W.

Philadelphia, PA 19106-1572;

USA

dtaichman@acponline.org

Cite this as:

Taichman DB, Backus J, Baethge C, Bauchner H, Flanagin A

Florenzano F, Frizelle FA, Godlee F, Gollogly L, Haileamlak A

Hong ST, Horton R, James A, Laine C, Miller PW, Pinborg A,

Rubin EJ, Sahni P: A disclosure form for work submitted to medical

journals-a proposal from the International Committee of Medical

Journal Editors. Dtsch Arztebl Int 2020;117: 61-3.

DOI: 10.3238/arztebl.2020.0061

This article is being published simultaneously in the following journals:

- Annals of Internal Medicine

- BMJ (British Medical Journal)

- Bulletin of the World Health Organization

- Deutsches Ärzteblatt

- Ethiopian Journal of Health Sciences

- JAMA (Journal of the American Medical Association)

- Journal of Korean Medical Science

- The Lancet

- New England Journal of Medicine (NEJM)

- New Zealand Medical Journal

- Revista Medica de Chile (Medical Journal of Chile)

- Ugeskrift for Laeger (Danish Medical Journal).

Note: Dr. Sahni's affiliation as representative and past president of the World Association of Medical Editors (WAME) does not imply endorsement by WAME member journals that are not part of the ICMJE. 